
\title{
$\begin{array}{ll}\text { Research Square } & \begin{array}{l}\text { Preprints are preliminary reports that have not undergone peer review. } \\ \text { They should not be considered conclusive, used to inform clinical practice, } \\ \text { or referenced by the media as validated information. }\end{array}\end{array}$
}

\section{Determination of the Influence of Peripheral Neuropathy Symptoms on Quality of Life in Breast Cancer Patients Receiving Paclitaxel: Prospective Cross Sectional Study With Four Follow-ups}

\section{BERNA KURT ( $\nabla$ bernacolakoglu85@gmail.com )}

Hacettepe Üniversitesi https://orcid.org/0000-0002-3299-7146

\section{ZEYNEP SIPAHI KARSLI}

Dr Abdurrahman Yurtaslan Ankara Oncology Training and Research Hospital: Ankara Dr Abdurrahman Yurtaslan Onkoloji Egitim ve Arastirma Hastanesi

\section{BERNA ÖMÜR ÇAKMAK ÖKSÜZOĞLU}

Dr Abdurrahman Yurtaslan Ankara Oncology Training and Research Hospital: Ankara Dr Abdurrahman Yurtaslan Onkoloji Egitim ve Arastirma Hastanesi

\section{EMINE ÖZTÜRK}

Dr Abdurrahman Yurtaslan Ankara Oncology Training and Research Hospital: Ankara Dr Abdurrahman Yurtaslan Onkoloji Egitim ve Arastirma Hastanesi

\section{NESLIHAN DEMIRÖRS}

Dr Abdurrahman Yurtaslan Ankara Oncology Training and Research Hospital: Ankara Dr Abdurrahman Yurtaslan Onkoloji Egitim ve Arastirma Hastanesi

\section{OSMAN DAĞ}

Hacettepe Üniversitesi: Hacettepe Universitesi

\section{Research Article}

Keywords: Peripheral neuropathy, quality of life, breast cancer, cross sectional study, follow-ups

Posted Date: November 15th, 2021

DOI: https://doi.org/10.21203/rs.3.rs-984164/v1

License: () (i) This work is licensed under a Creative Commons Attribution 4.0 International License. Read Full License 


\section{Abstract}

Background The objective of this study is to evaluate the impact of peripheral neuropathy on the quality of life of breast cancer patients throughout with monthly follow-up during 4 months of paclitaxel treatment.

Material and methods The research was conducted with a prospective cross sectional with four follow-ups descriptive design. The study population consisted of female patients with breast cancer at Ankara Oncology Training and Research Hospital between August 2018 and January 2019. Data were collected the "Patient Information Form”,"EORTC C30 Cancer Quality Of Life Questionnaire" and "Chemotherapy-Induced Peripheral Neuropathy Assessment Tool". The study was undertaken in accordance with the STROBE checklist for cross-sectional studies.

Results Of 79 patients included in the Chemotherapy-Induced Peripheral Neuropathy Assessment Tool except for the general activity subdimension were statistically significant in the ratings of $2^{\text {nd }}$, compared to $1^{\text {st. }} ; 3^{\text {rd }}$ compared to $1^{\text {st }}$ and $2^{\text {nd }} ; 4^{\text {th }}$ compared to $1^{\text {st }}, 2^{\text {nd }}$, and $3^{\text {rd }}$ follow-up periods. The overall mean of EORTC C30 Cancer Quality of Life Questionnaire, functional subdimension, symptom severity, and general well-being in the evaluations of $2^{\text {nd }}$, compared with $1^{\text {st. }} ; 3^{\text {rd }}$ compared with $1^{\text {st }}$ and $2^{\text {nd }} ; 4^{\text {th }}$ compared with $1^{\text {st }}, 2^{\text {nd }}$, and $3^{\text {rd }}$ follow-up periods it was found that the mean values of symptom that decreased gradually were statistically significant.

Conclusion The neuropathy scale was found to be higher in $2^{\text {nd }}, 3^{\text {rd }}, 4^{\text {th }}$ follow-up periods than in $1^{\text {st }}$ follow-up. Also, EORTC C30 Cancer QLQ subdimensions were high initially but gradually decreased after the fourth cycle. Thus, it was found that the increase in neuropathy symptoms negatively affects the quality of life.

\section{Background}

Chemotherapy, radiotherapy, surgical treatment, and immunotherapy are all used alone or in combination to treat breast cancer, the most prevalent type of cancer in women [1,2]. Symptoms are any undesirable effects that decrease a patient's quality of life and are perceived subjectively due to these treatments. Peripheral neuropathy is one of the symptoms associated with chemotherapy $[3,4]$. The effects of chemotherapeutic agents on the structural and functional areas of the nervous system cause chemotherapy-induced peripheral neurotoxicity (CIPN) [3-5].

The incidence of CIPN ranges from 61 to $92 \%$ due to the toxic impact of paclitaxel, an antineoplastic agent, on sensory neurons [6, 7]. Sensory, motor, and autonomic symptoms are observed in CIPN associated with paclitaxel. Stabbing-burning pain, burning, weakness, impaired walking and balance, constipation, sexual dysfunction, tingling, numbness, and increased sensitivity to heat/cold are among the symptoms $[8,9]$. Furthermore, sensory neuropathy induces complaints of sensory defects in the patient's extremities, defined as "as if wearing socks and gloves" $[5,10,11]$. Symptoms usually begin in the fingertips and progress distally to proximally [12-15]. Because these symptoms cause functional interference with activities of daily life, they negatively affect patients' physical, social, emotional, and functional health and reduce their quality of life. Patients treated every 21 days were assessed before and after at least six treatment sessions in a study analyzing sensory symptoms due to peripheral neurotoxicity results related to paclitaxel regimen, and symptoms were found to appear after the third cycle of treatment [16]. Support systems or treatment adherence play a significant role in diagnosis, treatment, the transition from illness to recovery, biopsychosocial adjustment, and patients' future expectations [17-20]. Effective detection of neuropathy causing possible trauma in patients receiving paclitaxel therapy is very important for treatment adherence and improvement of patients' quality of life. Therefore, it is necessary to effectively detect CIPN in its early stages [18-20]. By defining CIPN and taking the precautions required in the early stages, patients, nurses, and caregivers can monitor patients' quality of life and prevent worsening of symptoms.

In breast cancer patients, paclitaxel therapy is administered in weekly doses. The studies that assessed the patient quality of life and peripheral neuropathy in the literature reviews were evaluated as single-cycle follow-up [21]. No studies are using the Neuropathy Scale to assess the impact of peripheral neuropathy on quality of life currently and in detail and over a period of approximately four months throughout the treatment process. Therefore, this study aims to evaluate the impact of peripheral 
neuropathy on the quality of life of breast cancer patients throughout with monthly follow-up during 4 months of paclitaxel treatment. Transferring the study results to the clinical setting will allow management of the symptom of peripheral neuropathy experienced by patients from the beginning to the end of treatment, and an effective nursing process can be implemented.

\section{Material And Methods Research Design}

The study was conducted in a descriptive design with four prospective follow-ups. The study was conducted at Dr. Abdurrahman Yurtaslan Ankara Oncology Training and Research Hospital Chemotherapy Unit between August 2018 and January 2019.

\section{Population and Sample of the Research}

The study population consisted of female patients with breast cancer who received paclitaxel-based chemotherapy treatment in the outpatient chemotherapy department at Dr. Abdurrahman Yurtaslan Ankara Oncology Training and Research Hospital between August 2018 and January 2019. This study was executed and reported in accordance with STROBE Statement: guidelines for reporting cross-sectional studies. The study sample consisted of patients with breast cancer who met the inclusion criteria, $i$. aged 18-65 years, ii. on the first cycle of paclitaxel, an antineoplastic drug from the taxane group, iii. receiving weekly paclitaxel therapy, $i v$. without any communication disability. Patients who do not accept the study, $i$. who change their treatment regimen, ii. who discontinue treatment, iii. who are treated for less or more than 12 weeks, iv. with known neuropathy, $v$. with diabetes mellitus, uremia, thyroid disease, vi. Patients with systemic diseases causing polyneuropathy, and vii. Patients who had previously taken drugs causing neuropathy, such as paclitaxel, were excluded from the study. Initially, 238 patients were evaluated for compliance with the study criteria; 155 were not included in the study because they did not meet the criteria for the study (having Diabetes Mellitus (DM), uremia, thyroid disease, over 65 years old, did not want to participate in the study). For the study sample size, a pilot study was conducted with 20 breast cancer patients who had received four follow-up treatments with paclitaxel and completed the entire treatment process. It was determined that at least 72 patients should be included with a power of $80 \%$. The sample size at the beginning of the study was 83 patients, we completed the study with 79 patients because one patient left the study, the treatment of two patients was delayed due to blood values, and one patient wanted to move to a different city and receive the treatment in her hometown.

\section{Data Collection}

After obtaining ethics committee and institutional approvals, data were collected face-to-face by the researchers using the "Patient Information Form (PIF)","EORTC C30 Cancer Quality Of Life Questionnaire (EORTC C30 QLQ)" and "ChemotherapyInduced Peripheral Neuropathy Assessment Tool (CIPNAT)" patients who met the study criteria arrived at the institution where the study was conducted.

\section{Data Collection Tools}

PIF

The patient information form, which the researcher created by scanning the literature, consists of two parts. The first part consists of eight questions on socioeconomic characteristics. The second part consists of six disease-specific questions. Each patient's data collection on the form took 10-13 minutes.

CIPNAT

Tofthagen et al. [22] developed it to evaluate peripheral neuropathy induced by chemotherapy. First, the presence of 9 symptoms is rated on the scale, then the severity of symptoms, emotional distress, and frequency of occurrence. The second part of the scale also assessed the impact of these symptoms on 14 activities. These affected activities consist of the subdimensions dexterity and general activities. While dressing, writing, lifting, and holding objects are included in the hand 
skills subdimension, other activities are considered general activities. The total score resulting from the scale ranges from 0 to 279. A high score means that the severity and frequency of symptoms that complicate and hinder daily life are high [22]. Turkish validity of the scale was done by Kutlutürkan et al. in 2017 [23].

\section{EORTC C30 QLQ}

Aaronson et al. developed the EORTC C30 QLQ, which consists of 30 questions. Güzelant et al. adapted the EORTC C30 QLQ into Turkish and evaluated the validity and reliability of cancer patients in Turkey. The Cronbach's alpha coefficient of the scale was determined to be $\geq 0.70$ [24].

The EORTC C30 QLQ is a multidimensional scale that comprises a general health status and quality of life scale, five functional scales (physical function, role function, cognitive function, emotional function, and social function), and a symptom scale. The first 28 questions are a four-point Likert scale. High scores on the general well-being and functional scales indicate a high quality of life; low scores indicate a low quality of life [17]. Low scores in this section mean high quality of life; high scores mean low quality of life. The lowest total score they can achieve in scoring is 0 , and the highest score is 100 [24].

\section{Application of Research}

The investigators interviewed patients who met the study inclusion criteria before the first cycle of the paclitaxel regimen on day $0=F 1$. They were informed of the importance and purpose of the study and the patients' rights and that they could withdraw from the study at any time. The first interview lasted an average of 30-45 minutes, while the other interviews lasted 25-30 minutes. The first interview took place on F1 immediately before the paclitaxel regimen. Subsequent interviews were conducted after the end of the F2, F3 and F4 after the paclitaxel infusion ended.

\section{Statistical methods}

Statistical analyses were performed with SPSS 25.0 software. Descriptive data were presented as means and standard deviations, while categorical variables were described using frequency and percentage. Categorical variables were presented as number ( $\mathrm{n}$ ) and percentage (\%) values. Continuous variables were presented as median (IQR) (Interquartile Range) accordingly. Chi-square test was used to compare categorical data. In case of a statistically significant difference in the changes between the scale scores used in the study according to the courses, the advanced post-hoc test (Bonferronni Test) was used to determine the evaluation time $(\mathrm{F} 1, \mathrm{~F} 2, \mathrm{~F} 3, \mathrm{~F} 4)$ where the difference originated. A value of $\mathrm{p}<.05$ was considered statistically significant.

\section{Results}

The demographic characteristics and disease information of the patients $(n=79)$ participating in the study are shown in the following table with frequency and percentages. Accordingly the distribution of demographic characteristics, average age of patients is $46.10 \pm 0.85$, Body Surface Area (BSA): $1.70 \pm 0.01,57 \%$ of them are 46 years and older, $60.8 \%$ are married, and $50.6 \%$ of them have $1-2$ children. While $75.9 \%$ of patients had a primary school degree, $64.6 \%$ were housewives. While $58.2 \%$ of patients have a family history of cancer, $70.9 \%$ are not taking any medication other than CTx and have no history of any other disease. 
Table 1

Change of neuropathy and its sub-dimensions according to cycles

\begin{tabular}{|c|c|c|c|c|}
\hline Neuropathy Subdimensions & $\begin{array}{l}\text { 1st follow-up (F1) } \\
\text { (F1=Day } 0 \\
\text { of chemotherapy) }\end{array}$ & $\begin{array}{l}\text { 2nd Follow-up (F2) } \\
\text { (F2=4th cycle } \\
\text { of chemotherapy) }\end{array}$ & $\begin{array}{l}\text { 3rd Follow-up (F3) } \\
\text { (F3=8th cycle } \\
\text { of chemotherapy }\end{array}$ & $\begin{array}{l}\text { 4th Follow-up (F4) } \\
\text { (F4=12th cycle } \\
\text { of chemotherapy) }\end{array}$ \\
\hline Neuropathy overall & $0.00 \pm 0.00$ & $169.012 \pm 18.911$ & $265.189 \pm 13.636$ & $296.670 \pm 11.926$ \\
\hline$(M \pm S D) p<0.05$ & . & .000 & .000 & .000 \\
\hline $\begin{array}{l}\text { Sensory symptoms } \\
(M \pm S D) p<0.05\end{array}$ & $0.00 \pm 0.00$ & $\begin{array}{l}86.151 \pm 14.348 \\
.000\end{array}$ & $\begin{array}{l}126.354 \pm 10.387 \\
.000\end{array}$ & $\begin{array}{l}147.860 \pm 7.420 \\
.000\end{array}$ \\
\hline $\begin{array}{l}\text { Motor symptoms } \\
(M \pm S D) p<0.05\end{array}$ & $0.00 \pm 0.00$ & $35.493 \pm 4.193$ & $47.683 \pm 4.524$ & $53.784 \pm 3.070$ \\
\hline $\begin{array}{l}\text { Dexterity activities } \\
(M \pm S D) p<0.05\end{array}$ & $0.00 \pm 0.00$ & $\begin{array}{l}15.987 \pm 2.041 \\
.000\end{array}$ & $\begin{array}{l}28.341 \pm 1.934 \\
.000\end{array}$ & $\begin{array}{l}32.987 \pm 2.589 \\
.000\end{array}$ \\
\hline $\begin{array}{l}\text { General activity } \\
(M \pm S D) p<0.05\end{array}$ & $0.00 \pm 0.00$ & $\begin{array}{l}31.379 \pm 3.317 \\
.000\end{array}$ & $\begin{array}{l}62.810 \pm 2.511 \\
.000\end{array}$ & $\begin{array}{l}62.038 \pm 3.642 \\
.000\end{array}$ \\
\hline
\end{tabular}

Table 1. displays the change of neuropathy and its sub-dimensions according to cycles. Accordingly, the overall average of neuropathy, sensory symptoms, motor symptoms, dexterity, F2, F3, F4 follow-up scores were significantly higher than F1 $(p<0.05)$. For the subdimensions of general activity, the mean scores of F2 follow-ups were significantly higher compared to F1 $(p<0.05)$, while the mean scores of F3 and F4 follow-ups were significantly lower $(p<0.05)$.

Table 2

Comparison of neuropathy according to follow-up times

\begin{tabular}{|c|c|c|c|c|c|c|c|c|c|c|c|}
\hline \multicolumn{2}{|c|}{ Variables } & \multirow{2}{*}{$\begin{array}{l}\begin{array}{l}\text { Neuropathy } \\
\text { overall } \\
\text { mean }\end{array} \\
-169.013^{*}\end{array}$} & \multirow{2}{*}{$\begin{array}{l}\mathbf{p} \\
.000\end{array}$} & \multirow{2}{*}{$\begin{array}{l}\begin{array}{l}\text { Neuropathy } \\
\text { sensory } \\
\text { symptoms }\end{array} \\
-86.152^{*}\end{array}$} & \multirow{2}{*}{$\begin{array}{l}\mathbf{p} \\
.000\end{array}$} & \multirow{2}{*}{$\begin{array}{l}\begin{array}{l}\text { Neuropathy } \\
\text { Motor } \\
\text { symptoms }\end{array} \\
-35.494^{\star}\end{array}$} & \multirow{2}{*}{$\begin{array}{l}\mathbf{p} \\
.000\end{array}$} & \multirow{2}{*}{$\begin{array}{l}\text { Neuropathy } \\
\text { General } \\
\text { Activity }\end{array}$} & \multirow{2}{*}{$\begin{array}{l}\mathbf{p} \\
.000\end{array}$} & \multirow{2}{*}{$\begin{array}{l}\text { Neuropathy } \\
\text { Dexterity } \\
\text { Activities }\end{array}$} & \multirow{2}{*}{$\begin{array}{l}\mathbf{p} \\
.000\end{array}$} \\
\hline F1 & $\mathrm{F} 2$ & & & & & & & & & & \\
\hline & F3 & $-265.190^{*}$ & .000 & $-126.354^{*}$ & .000 & $-47.684^{*}$ & .000 & $-62.810^{*}$ & .000 & $-28.342^{*}$ & .000 \\
\hline & $\mathrm{F} 4$ & $-296.671^{*}$ & .000 & $-147.861^{*}$ & .000 & $-53.785^{\star}$ & .000 & $-62.038^{*}$ & .000 & $-32.987^{\star}$ & .000 \\
\hline \multirow[t]{3}{*}{ F2 } & F1 & $169.013^{*}$ & .000 & $86.152^{*}$ & .000 & $35.494^{*}$ & .000 & $31.380^{*}$ & .000 & $15.987^{*}$ & .000 \\
\hline & F3 & $-96.177^{*}$ & .000 & $-40.203^{\star}$ & .000 & $-12.190^{\star}$ & .000 & $-31.430^{\star}$ & .000 & $-12.354^{*}$ & .000 \\
\hline & $\mathrm{F} 4$ & $-127.658^{*}$ & .000 & $-61.709^{\star}$ & .000 & $-18.291^{*}$ & .000 & $-30.658^{\star}$ & .000 & $-17.000^{\star}$ & .000 \\
\hline \multirow[t]{3}{*}{ F3 } & $\mathrm{F} 1$ & $265.190^{*}$ & .000 & $126.354^{\star}$ & .000 & $47.684^{*}$ & .000 & $62.810^{*}$ & .000 & $28.342^{*}$ & .000 \\
\hline & $\mathrm{F} 2$ & $96.177^{\star}$ & .000 & $40.203^{*}$ & .000 & $12.190^{\star}$ & .000 & $31.430^{*}$ & .000 & $12.354^{*}$ & .000 \\
\hline & $\mathrm{F} 4$ & $-31.481^{*}$ & .000 & $-21.506^{*}$ & .000 & $-6.101^{*}$ & .000 & .772 & .865 & $-4.646^{*}$ & .000 \\
\hline \multirow[t]{3}{*}{ F4 } & $\mathrm{F} 1$ & $296.671^{*}$ & .000 & $147.861^{*}$ & .000 & $53.785^{\star}$ & .000 & $62.038^{*}$ & .000 & $32.987^{\star}$ & .000 \\
\hline & $\mathrm{F} 2$ & $127.658^{*}$ & .000 & $61.709^{*}$ & .000 & $18.291^{*}$ & .000 & $30.658^{*}$ & .000 & $17.000^{*}$ & .000 \\
\hline & F3 & $31.481^{\star}$ & .000 & $21.506^{*}$ & .000 & $6.101^{*}$ & .000 & -.772 & .865 & $4.646^{*}$ & .000 \\
\hline
\end{tabular}


Table 2. demonstrates the comparison of neuropathy according to the F1, F2, F3 and F4. Accordingly, it was found that, except for the General Activity subdimension, the mean values of the increasing symptom subdimensions were statistically significant $(\mathrm{p}<0.05)$ in the ratings of F2 compared to F1, F3 compared to F1 and F2, F4 compared to F1, F2 and F3.

In addition to when examining the age-related changes in the F1, F2, F3 and F4 of the CIPNAT scale during the patients' paclitaxel regimen, it was found that the mean scores during the four follow-ups (F1, F2, F3, F4) were not statistically significant $(p>0.05)$.

Table 3

Change in quality of life and its subdimensions depending on the cycle

\begin{tabular}{|c|c|c|c|c|}
\hline \multirow[t]{2}{*}{$\begin{array}{l}\text { Quality Of Life } \\
\text { Subdimension }\end{array}$} & $\begin{array}{l}\text { 1st follow-up } \\
\text { (F1) }\end{array}$ & $\begin{array}{l}\text { 2. Follow-up } \\
\text { (F2) }\end{array}$ & $\begin{array}{l}\text { 3. Follow-up } \\
\text { (F3) }\end{array}$ & $\begin{array}{l}\text { 4. Follow-up } \\
\text { (F4) }\end{array}$ \\
\hline & $\begin{array}{l}\text { (F1=Day } 0 \text { of } \\
\text { chemotherapy) }\end{array}$ & $\begin{array}{l}\text { (F2=4th cycle of } \\
\text { chemotherapy) }\end{array}$ & $\begin{array}{l}\text { (F3=8th cycle of } \\
\text { chemotherapy) }\end{array}$ & $\begin{array}{l}\text { (F4=12th cycle of } \\
\text { chemotherapy) }\end{array}$ \\
\hline Grand total & $98.234 \pm 0.000$ & $66.448 \pm 4.837$ & $51.617 \pm 6.406$ & $32.791 \pm 4.967$ \\
\hline$(M \pm S D) p$ & .000 & .000 & .000 & .000 \\
\hline \multirow{2}{*}{$\begin{array}{l}\text { Functional } \\
\text { subdimension } \\
(\mathrm{M} \pm \mathrm{SD}) \mathbf{p}\end{array}$} & $1.000 \pm 0.000$ & $0.644 \pm .066$ & $0.490 \pm 060$ & $0.323 \pm .062$ \\
\hline & .000 & .000 & .000 & .000 \\
\hline Symptom severity & $1.000 \pm 0.000$ & $0.718 \pm .056$ & $0.555 \pm .094$ & $0.357 \pm .057$ \\
\hline$(M \pm S D) \mathbf{p}$ & .000 & .000 & .000 & .000 \\
\hline General Well-Being & $0.735 \pm 0.104$ & $0.465 \pm 0.116$ & $0.457 \pm 0.051$ & $0.169 \pm 0.083$ \\
\hline$(M \pm S D) p$ & .000 & .000 & .000 & .000 \\
\hline
\end{tabular}

Table 3. contains the results of the change in quality of life and its subdimensions depending on the cycle at the F1, F2, F3 and F4. Accordingly, the general average of quality of life, functional subdimensions, symptom severity, general well-being, and the mean scores of follow-ups F2, F3, and F4 were significantly lower than F1 $(p<0.05)$. 
Table 4

Comparison of quality of life according to follow-up periods

\begin{tabular}{|c|c|c|c|c|c|c|c|c|c|}
\hline \multicolumn{2}{|c|}{ Variables } & \multirow{2}{*}{$\begin{array}{l}\text { Grand Total } \\
31.786^{*}\end{array}$} & \multirow{2}{*}{$\begin{array}{l}\mathbf{p} \\
.000\end{array}$} & \multirow{2}{*}{$\begin{array}{l}\text { Functional subdimension } \\
.356^{*}\end{array}$} & \multirow{2}{*}{$\begin{array}{l}\mathbf{p} \\
.000\end{array}$} & \multirow{2}{*}{$\begin{array}{l}\text { Symptom } \\
\text { severity } \\
.281^{*}\end{array}$} & \multirow{2}{*}{$\begin{array}{l}\mathbf{p} \\
.000\end{array}$} & \multirow{2}{*}{$\begin{array}{l}\text { General Well-Being } \\
.270^{*}\end{array}$} & \multirow{2}{*}{$\begin{array}{l}\mathbf{p} \\
.000\end{array}$} \\
\hline F1 & $\mathrm{F} 2$ & & & & & & & & \\
\hline & F3 & $46.617^{\star}$ & .000 & $.510^{*}$ & .000 & $.445^{\star}$ & .000 & $.277^{\star}$ & .000 \\
\hline & $\mathrm{F} 4$ & $65.443^{*}$ & .000 & $.676^{*}$ & .000 & $.643^{*}$ & .000 & $.565^{\star}$ & .000 \\
\hline \multirow[t]{3}{*}{$\mathrm{F} 2$} & $\mathrm{~F} 1$ & $-31.786^{*}$ & .000 & $-.356^{*}$ & .000 & $-.281^{*}$ & .000 & $-.270^{*}$ & .000 \\
\hline & F3 & $14.831^{*}$ & .000 & $.154^{*}$ & .000 & $.163^{\star}$ & .000 & .007 & 1.000 \\
\hline & $\mathrm{F} 4$ & $33.657^{\star}$ & .000 & $.320^{*}$ & .000 & $.362^{*}$ & .000 & $.295^{\star}$ & .000 \\
\hline \multirow[t]{3}{*}{ F3 } & $\mathrm{F} 1$ & $-46.617^{*}$ & .000 & $-.510^{\star}$ & .000 & $-.445^{*}$ & .000 & $-.277^{\star}$ & .000 \\
\hline & $\mathrm{F} 2$ & $-14.831^{*}$ & .000 & $-.154^{*}$ & .000 & $-.163^{*}$ & .000 & -.007 & 1.000 \\
\hline & F4 & $18.826^{*}$ & .000 & $.166^{*}$ & .000 & $.198^{*}$ & .000 & $.288^{*}$ & .000 \\
\hline \multirow[t]{3}{*}{ F4 } & F1 & $-65.443^{*}$ & .000 & $-.676^{*}$ & .000 & $-.643^{*}$ & .000 & $-.565^{\star}$ & .000 \\
\hline & $\mathrm{F} 2$ & $-33.657^{*}$ & .000 & $-.320^{*}$ & .000 & $-.362^{*}$ & .000 & $-.295^{*}$ & .000 \\
\hline & F3 & $-18.826^{*}$ & .000 & $-.166^{*}$ & .000 & $-.198^{*}$ & .000 & $-.288^{*}$ & .000 \\
\hline
\end{tabular}

In Table 4. contains the results of the comparison of quality of life according to follow-up periods. Accordingly, for the overall mean of quality of life, functional subdimension, symptom severity, and general well-being in the evaluations of F2 compared with F1; F3 compared with F1, and F2; F4 compared with F1, F2, and F3, it was found that the mean values of symptom subdimensions that decreased gradually were statistically significant $(p<0.05)$. In addition to the normality assumptions of the scores of the frequency of symptom sub-dimension according to the changes between the EORTC C30 QLQ and CIPNAT

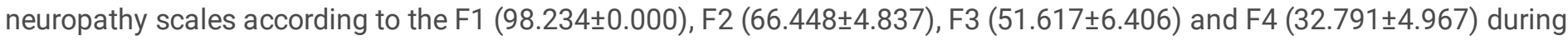
the paclitaxel regimen was examined, and it was seen that all scores met the assumption of normality. Therefore, Pearson Correlation Coefficient was used to study the relationship between the values. F4 was found to have a statistically moderately significant linear relationship, while a significant linear relationship was observed in all other follow-ups $(p<0.05)$.

In Graphics 1. demonstrates the the relationship between the neuropathy dexterity subdimension and the functional subdimension EORTC C30 QLQ at F1, F2, F3 and F4 of the CIPNAT scale during paclitaxel regimen of the patients, it was found that the mean scores during F2 and F4 were statistically significant $(p<0.05)$.

When the data on the frequency and percentage values of the symptoms occurring after chemotherapy in the F1, F2, F3 and F4 were examined during the paclitaxel regimen, it was found that they suffered most from insomnia (83.3\%) in F1, loss of appetite (64.9\%) and fatigue (78.2\%) in F2, and most from fatigue in F3 (83.7\%) and F4 (94.2\%). In addition to the frequency and percentage values of symptoms to time to experience neuropathy symptoms according to cycles at F1, F2, F3 and F4 as well as the duration of symptoms associated with neuropathy during the patients' paclitaxel regimen. It was found to last no more than 1-3 days in F2 (53.2\%) and no more than 3-7 days in F3 (58.2\%) and F4 (67.1\%). Also, the frequency and percentage values to used the manage chemotherapy symptoms at the F1, F2, F3 and F4, it was found that they used religious practices, exercise practices, and rubs (massages) from nonpharmacological uses in F2 (72.8\%), F3 (74.2\%), and F4 (82.7\%) and took acetaminophen to cope with neuropathy in F2, F3 (1.3\%), and F4 (2\%) in pharmacological methods.

\section{Discussion}


Chemotherapy-associated peripheral neuropathy is a common and serious consequence of cancer treatment. Because it is often the main reason for treatment reduction or discontinuation, it may affect survival by limiting the effectiveness of treatment. It will facilitate the screening of chemotherapy-induced peripheral neuropathies and their intervention in patients' daily lives [25]. Brouwers et al. (2009) reported in a pilot study that examined persistent neuropathy for up to six years after treatment with cisplatin and oxaliplatin that in patients who completed a cisplatin and oxaliplatin treatment regimen, peripheral neuropathy symptoms continued as chronic peripheral neuropathy in the lower extremities, particularly in the feet, and their quality of life was impaired [26]. Eckhoff et al. (2015) reported that in 15\% of breast cancer survivors treated with docetaxel, there was a significant relationship between peripheral neuropathy symptoms observed 1-3 years after treatment [27]. Because there are no study data in the literature covering all four follow-up processes similar to our study, the follow-ups were evaluated individually. In our study, the duration of the neuropathy-related symptoms was found that they lasted no more than 1-3 days in F2 and no more than 3-7 days in F3 and F4. These times are thought to be dependent on a 7-day (weekly paclitaxel) cycle of treatment.

Sensory, motor, and autonomic symptoms are observed in CIPN associated with paclitaxel. These symptoms include stabbingburning pain, burning, weakness, difficulty walking, balance, constipation, sexual dysfunction, tingling, numbness, and increased sensitivity to heat/cold $[8,9]$. Furthermore, sensory neuropathy causes complaints of sensory disturbances in the patient's extremities, defined as "as if wearing socks and gloves" $[5,10,11]$. Symptoms usually begin at the fingertips and progress from distal to proximal [12-15]. Because these symptoms cause functional disorders in daily activities, they have a negative impact on patients' physical, social, emotional, and functional health and their quality of life [28]. In the study by Seretny et al. (2014), more than $60 \%$ of patients reported experiencing more or less severe symptoms of chemotherapy-induced peripheral neuropathy after the first month following completion of chemotherapy, and these symptoms lasted for a long time [29]. In our study, when comparing the symptom subdimensions according to the general average, sensory symptoms, motor symptoms, and manual dexterity activities increasing mean values of the symptom subdimensions were found in the ratings from F2 compared to F1, F3 compared to F1 and F2, F4 compared to F1, F2, and F3, which were statistically significant. We believe that these progressive changes in neuropathy subdimensions in recent cycles are due to the increase in cumulative dose.

In the Arabic version of the assessment tool for chemotherapy-induced peripheral neuropathy by Obaid et al. (2020), patients most frequently reported numbness in the fingers/feet and numbness in the fingers/hands as severity, distress, and frequency of symptoms ( $54.1 \%$ and $51.1 \%$, respectively), followed by muscle or joint pain and tingling in the feet/toes $(43.7 \%$ and $42.2 \%$, respectively) [30]. According to our study, in the sub-dimensions of general mean, sensory symptoms, motor symptoms, and manual dexterity activities in the evaluations of F2 compared to F1, F3 compared to F1 and F2, F4 compared to F1, F2, and F3, the increasing mean scores of symptom sub-dimensions were found to be statistically significant, which is consistent with the literature.

In the study by Obaid et al. (2020), patients' responses to the frequency of symptom interaction items indicate that neuropathic symptoms affected walking, sleep, and usual housework in more than $40 \%$ of participants treated with neurotoxic chemotherapy. Neuropathic symptoms impaired enjoyment of life, exercise, participation in hobbies or recreational activities, and writing in more than $30 \%$ of participants treated with neurotoxic chemotherapy, with the least discomfort occurring during driving (18.5\%) [30]. In our study, the smallest effect was in part about driving. We attribute this to the educational level of breast cancer patients (75.9\% in primary school) and, accordingly, the proportion of drivers.

Hershman et al. (2011) reported that, the relationship between patient-reported outcomes and quantitative sensory testing to measure long-term neurotoxicity in breast cancer survivors treated with adjuvant paclitaxel chemotherapy, it was found that $81 \%$ of 50 breast cancer patients reported numbness in the hands or feet in the last week and $27 \%$ of these symptoms occurred in the hands, while $25 \%$ of them reported severe symptoms in the feet [31]. Considering that the first six questions of the CIPNAT scale, included sensory symptoms in our patient group, their severity and frequency gradually increased throughout the treatment period in processes F2, F3, and F4. This situation is thought to improve progressively depending on the cumulative dose of the paclitaxel treatment regimen. 
In a retrospective 7-year, follow-up study examining the impact of oxaliplatin-induced peripheral neuropathy on health-related quality of life in survivors of colorectal cancer, Tofthagen et al. (2013) found that at least one symptom persisted in the posttreatment period, and the symptom of insomnia was significantly associated with the symptom of neuropathy [15]. The patients followed up for 25 months after oxaliplatin treatment, peripheral neuropathy symptoms continued to occur in $79.2 \%$ of patients, particularly sensory symptoms after treatment, and there was a significant correlation between neuropathy symptom scores and the cumulative dose of oxaliplatin administered [32]. In our study, although insomnia was most frequently observed at the first follow-up (without treatment), it also increased in F2 and F4. Insomnia that occurs without taking the first treatment cycle is thought to be due to the uncertainty and anxiety associated with chemotherapy. Insomnia that occurs with subsequent cycles is thought to be more related to the symptoms of neuropathy.

The association between age and taxane-based chemotherapy, treatment-related neurotoxic effects were reported to increase with age in elderly female patients with a mean follow-up of 8.5 years [33]. In our study it was found that the mean values during the four follow-ups (F1, F2, F3, F4) were not statistically significant. The inconsistency of age and neuropathy symptoms with the literature is because the mean age of patients in our treatment group was 46.10 years, and the percentages under 45 years and over 46 years were $43.0 \%$ and $57.0 \%$, respectively.

Considering the cumulative doses of taxane-based drugs that cause peripheral neuropathy grade 2-4 peripheral neuropathy has been reported to occur due to paclitaxel treatment at an average dose of $715-1500 \mathrm{mg} / \mathrm{m} 2$ [24, 34]. The study that potential risk factors for falls in people with CIPN, including cumulative dose and number of cycles, severity of loss of balance, severity of muscle weakness, self-reported impairment in walking or driving, number of neuropathic symptoms, severity of CIPN, and performance [35]. Also, patients who had fallen scored significantly higher on the CIPNAT, including the number of symptoms, symptom life items, and intervention items, than patients who had not fallen [35]. In our study, the mean BSA was $1.70 \pm 0.01$ and according to the neuropathy-related changes in the CIPNAT scale during the patients' paclitaxel regimen, the frequency of the motor symptoms subdimension and the mean of the F2, F3, F4 follow-ups are significantly higher than the F1 ( $p<0.05)$. This is hypothesized to increase with cumulative dose.

Although literature reviews have reported that some pharmacologic uses such as calcium and magnesium, as well as nonpharmacologic approaches such as acupuncture, massage, exercise, etc., may be beneficial, there are no uses with proven efficacy in the prevention or management [36]. According to our study, management of symptoms related to neuropathy it was found that our patients used religious practices, movement exercises, and rubbing methods (massage) from the nonpharmacological practices in F2, F3, and F4, and pharmacological procedures $\mathrm{F} 2, \mathrm{~F} 3$, and $\mathrm{F} 4$ were determined to take paracetamol to manage neuropathy. In this context, it is thought that although data compatible with the literature are obtained, complete success in management has not been achieved.

Examining the studies in the literature to manage peripheral neuropathy and improvement of patients' quality of life, exercise is reported to reduce motor deficits in peripheral neuropathy, (tingling, numbness, and sensitivity to cold/heat) and neuropathic pain scores [37-40]. In a pilot study examining the effect of a somatic yoga and meditation intervention (SYM) on functional outcomes and quality of life, SYM was performed twice weekly for a period of 8 weeks; the intervention was found to contribute positively to functional measures of quality of life in patients with CIPN [41]. A randomized controlled study that included an individualized six-week moderate-intensity progressive home walking and resistance exercise program reported that patients receiving taxane, platinum, or vinca-alkaloid-based chemotherapy had decreased symptoms of CIPN, and an exercise program was recommended for these patient groups [42]. In the study which examined the association between chemotherapy-induced neuropathy and quality of life in colorectal cancer survivors 2 to 11 years later, it was reported that patients had neuropathyrelated symptoms, particularly sensory symptoms in the lower extremities. Because neuropathy symptoms negatively affect the quality of life, the importance of screening for these symptoms is particularly emphasized [43]. In our study the symptoms that occurred during the cycle of paclitaxel and the data on the management of symptoms associated with neuropathy were examined, it was found that they used religious practices, movement exercises, and rubs (massages) in the nonpharmacological applications in F2, F3, and F4 and took paracetamol to manage neuropathy in the pharmacological methods in F2, F3, and F4. Although the data are consistent with the literature, the CIPNAT scale and quality of life scale indicate no complete success in management. Also, the relationship between peripheral neuropathy and quality of life in our 
study, also show the results of the symptom subdimension according to neuropathy-related changes in the CIPNAT scale and the symptom subdimension according to changes in the EORTC C30 QLQ during patients' paclitaxel regimen. According to the results of correlation analysis in both scales, the CIPNAT scale increased in evaluations F2 compared to F1, F3 compared to F1 and F2, F4 compared to F1, F2, and F3, while the dimensions of EORTC C30 QLQ statistically decreased. In addition, when the relationship between the neuropathy subdimension of manual dexterity in the CIPNAT scale and the functional subdimension of the EORTC C30 QLQ was examined, it was found that the mean scores during F2 and F4 were statistically significant. Thus, it was found that the increase in neuropathy symptoms negatively affects the quality of life. It was found that there was a negative relationship between sensory, motor, and hand skills and quality of life. This result of our study is consistent with the literature.

\section{Conclusion}

Our study demonstrates, in breast cancer patients, the general mean score of paclitaxel regimen according to the CIPNAT neuropathy scale, sensory symptoms, motor symptoms, symptom frequency, duration, and severity of manual dexterity activities was found to be higher in F2, F3, F4 follow-up periods than in F1. Accordingly, patients' neuropathy symptom subdimensions gradually increased after the first follow-up. In addition, the subdimensions of general activity related to neuropathy had higher scores at the first follow-up, whereas a decrease in neuropathy symptoms was observed at the F3 and F4 follow-up. It was found that EORTC C30 QLQ subdimensions were high initially but gradually decreased after the fourth cycle of paclitaxel. Also, it was found that there was a negative correlation between patients' neuropathy-related quality of life scores and that quality of life decreased with increasing neuropathy scores.

\section{Declarations}

\section{Funding}

The author(s) received no financial support for the research, authorship, and/or publication of this article.

\section{Declaration of Conflicting Interests}

The author(s) declared no potential conflicts of interest with respect to the research, authorship, and/or publication of this article.

\section{Availability of data and materials}

The analyzable dataset may be requested from the authors upon reasonable request and permission.

\section{Code availability}

Not applicable.

\section{Author contribution}

BK, ZSK, BÖçÖ contributed to the concept design of the study, conceptualization and methodology

BK, ZSK, EÖ, ND contributed to the data collection,

BK, OD were responsible for the data analysis.

BK, ZSK, BÖÇÖ were responsible for interpretation of results and drafting the masnuscript. All authors read and approved the fnal manuscript.

\section{Ethics approval}


Before answering the questionnaire, the researchers informed the patients of the study's purpose, their rights, and the fact that they could withdraw from the research at any time. All eligible participants provided informed consent before they completed the questionnaire. This study was approved by the University of Health Sciences Clinical Research Ethics Committee (KA-201808/129) before data collection began. All interventions were carried out in accordance with institutional ethical standards and the national research committee, including the 1964 Declaration of Helsinki and subsequent amendments. The PIT was administered to the patients who gave written and oral consent on the first day of the study. A written interview was performed with every patient individually.

\section{Consent to participate}

Not applicable.

\section{Consent for publication}

Not applicable.

\section{Competing interests}

The authors declare no competing interests.

\section{References}

1. Karayurt Ö, Andıç S (2011) Breast Care Nursing. Journal of Breast Health7(4):196-202.

2. Saklı K, Demir-Zencirci A (2013) Nursing Interventions of Chemotherapyinduced peripheral neuropathy and neuropathic pain in patients receiving taxanes and platino: A literature review. Journal of Research and Development in Nursing 15(1):61-73.

3. Loprinzi CL, Lacchetti C, Bleeker J, Cavaletti G, Chauhan C, Hertz DL, Hershman DL (2020) Prevention and management of chemotherapy-induced peripheral neuropathy in survivors of adult cancers: ASCO guideline update. Journal of Clinical Oncology38(28):3325-3348.

4. Kautio AL, Haanpää M, Kautiainen H, Kalso E, Saarto T (2011) Burden of chemotherapy-induced neuropathy-a crosssectional study. Supportive Care in Cancer19(12):1991-1996.

5. Massey RL, Kim HK, Abdi S (2014) Brief review: chemotherapy-induced painful peripheral neuropathy (CIPPN): current status and future directions. Canadian Journal of Anesthesia/Journal canadien d'anesthésie61(8):754-762.

6. Beijers AJ, Jongen JL, Vreugdenhil G (2012) Chemotherapy-induced neurotoxicity: the value of neuroprotective strategies. Neth J Med70(1):18-25.

7. Colvin LA (2019) Chemotherapy-induced peripheral neuropathy (CIPN): where are we now?. Pain160(1):1-10.

8. Dorsey SG, Kleckner IR, Barton D et al (2019) The national cancer institute clinical trials planning meeting for prevention and treatment of chemotherapy-induced peripheral neuropathy. JNCl: Journal of the National Cancer Institute111(6):531537.

9. Arıkan F, Kurt S (2014) Peripheral Neuropathy. In: Can G (ed) Oncology Nursing. Nobel Medical Bookstore, İstanbul, pp 489495.

10. Kanbayashi Y, Hosokawa T, Okamoto K et al (2010) Statistical identification of predictors for peripheral neuropathy associated with administration of bortezomib, taxanes, oxaliplatin or vincristine using ordered logistic regression analysis. Anti-cancer drugs21(9):877-881.

11. Kösemen D, Akın S (2016) Chemotherapy-Induced Peripheral Neurotoxicity and Nursing Interventions for Management of Peripheral Neurotoxicity. Health and Society 26(3):26-36.

12. Diaz M, Schiff D (2020) Neurological Complications of Chemotherapy. In: Central Nervous System Metastases.Springer, Cham pp 329-340. 
13. Kannarkat G, Lasher EE, Schiff D (2007) Neurologic complications of chemotherapy agents. Current opinion in neurology20(6): 719-725.

14. Tofthagen C (2010) Patient perceptions associated with chemotherapy-induced peripheral neuropathy. Clinical journal of oncology nursing14(3):22-29.

15. Tofthagen C, Visovsky C, Rodriguez R (2013) Chemotherapy-induced peripheral neuropathy: an algorithm to guide nursing management. Clinical journal of oncology nursing17(2):138

16. Cavaletti G, Bogliun G, Marzorati L et al (1995) Peripheral neurotoxicity of taxol in patients previously treated with cisplatin. Cancer75(5):1141-1150.

17. Byar KL, Berger AM, Bakken SL, et al (2006) Impact of adjuvant breast cancer chemotherapy on fatigue, other symptoms, and quality of life. Oncol Nurs Forum 33(1):18-26.

18. Park HJ, Bae SH, Jung YS et al (2011) Quality of life and symptom experience in breast cancer survivors after participating in a psychoeducational support program: A pilot study. Cancer Nurs 35(1):34-41.

19. Salonen P, Kellokumpu-Lehtinen PL, Tarkka MT et al (2011) Changes in quality of life in patients with breast cancer. Journal of clinical nursing 20(1-2):255-266.

20. Pinto AC, de Azambuja E (2011) Improving quality of life after breast cancer: dealing with symptoms. Maturitas 70(4):343348.

21. Önsüz Ü, Can G (2020) Taksan Bazlı Tedavi İle Illişkili Periferal Nöropatinin Yönetiminde Girişim Uygulayan Ve Uygulamayan Hastaların Yaşam Kalitesi. Izmir Democracy University Health Sciences Journal 3(2):114-134.

22. Tofthagen CS, McMillan SC, Kip KE (2011) Development and psychometric evaluation of the chemotherapy-Induced peripheral neuropathy assessment tool. Cancer Nurs 34:10-20.

23. Kutlutürkan S, Öztürk ES, Arıkan F et al (2017) The psychometric properties of the Turkish version of the ChemotherapyInduced Peripheral Neuropathy Assessment Tool (CIPNAT). European Journal of Oncology Nursing 31:84-89.

24. Güzelant A, Göksel T, Özkök S, et al (2004) The European Organization for Research and Treatment of Canser QLQ-C30: an examination into the cultural validity and reliability of the Turkish version of the EORTC QLQ-C30, European Journal of Cancer Care 13:135-144.

25. Argyriou AA, Kyritsis AP, Makatsoris T et al (2014) Chemotherapy-induced peripheral neuropathy in adults: a comprehensive update of the literature. Cancer management and research6: 135-147.

26. Brouwers EE, Huitema AD, Boogerd W et al (2009) Persistent neuropathy after treatment with cisplatin and oxaliplatin. Acta Oncologica 48(6):832-841.

27. Eckhoff L, Knoop AS, Jensen M (2015) Persistence of docetaxel-induced neuropathy and impact on quality of life among breast cancer survivors. European Journal of Cancer 51(3):292-300.

28. Uçar MA (2017) Chemotherapy-induced chronic peripheral neuropathy and its effect on quality of life. Master's Thesis, Akdeniz University.

29. Seretny M, Currie GL, Sena ES et al (2014) Incidence, prevalence, and predictors of chemotherapy-induced peripheral neuropathy: a systematic review and meta-analysis. Pain 155(12):2461-2470..

30. Obaid A, El-Aqoul A, Alafafsheh A et al (2020) Validation of the Arabic Version of the Chemotherapy-Induced Peripheral Neuropathy Assessment Tool. Pain Management Nursing21(6): 587-593.

31. Hershman DL, Lacchetti C, Dworkin RH et al (2014) Prevention and management of chemotherapy-induced peripheral neuropathy in survivors of adult cancers: American Society of Clinical Oncology clinical practice guideline. J Clin Oncol 32(18): 1941-1967.

32. Park SB, Lin CS, Krishnan AV et al (2011) Long-term neuropathy after oxaliplatin treatment: challenging the dictum of reversibility. The oncologist16(5):708.

33. Lichtman SM, Hurria A, Cirrincione CT et al (2012) Paclitaxel efficacy and toxicity in older women with metastatic breast cancer: Combined analysis of calgb 9342 and 9840. Annals of Oncology 23(3): 632-638. https://doi.org/10.1093/annonc/mdr297 
34. Ewertz M, Qvortrup C, Eckhoff L (2015) Chemotherapy-induced peripheral neuropathy in patients treated with taxanes and platinum derivatives. Acta Oncologica 54(5): 587-591. https://doi.org/10.3109/0284186X.2014.995775

35. Tofthagen C, Overcash J, Kip K (2012) Falls in persons with chemotherapy induced peripheral neuropathy. Supportive care in cancer 20(3): 583-589.

36. Loprinzi CL, Lacchetti C, Bleeker J et al (2020) Prevention and Management of Chemotherapy-Induced Peripheral Neuropathy in Survivors of Adult Cancers: ASCO Guideline Update. Journal of Clinical Oncology 38 (28): 3325-3348. https://doi.org/10.1200/jco.20.01399

37. Dhawan S, Andrews R, Kumar L et al (2020) A Randomized Controlled Trial to Assess the Effectiveness of Muscle Strengthening and Balancing Exercises on Chemotherapy-Induced Peripheral Neuropathic Pain and Quality of Life Among Cancer Patients. Cancer Nursing 43(4): 269-280. https://doi.org/10.1097/ncc.0000000000000693

38. Duregon F, Vendramin B, Bullo V et al (2018) Effects of exercise on cancer patients suffering chemotherapy-induced peripheral neuropathy undergoing treatment: A systematic review. Critical Reviews in Oncology/Hematology 121: 90-100. https://doi.org/10.1016/j.critrevonc.2017.11.002

39. Greenlee H, Hershman DL, Shi Z et al (2017) BMI, Lifestyle Factors and Taxane-Induced Neuropathy in Breast Cancer Patients: The Pathways Study. JNCl: Journal of the National Cancer Institute109(2):1-8 https://doi.org/10.1093/jnci/djw206

40. Zimmer P, Trebing S, Timmers-Trebing $U$ et al (2018) Eight-week, multimodal exercise counteracts a progress of chemotherapy-induced peripheral neuropathy and improves balance and strength in metastasized colorectal cancer patients: a randomized controlled trial. Supportive Care in Cancer 26(2): 615-624. https://doi.org/10.1007/s00520-0173875-5

41. Galantino ML, Tiger R, Brooks J et al (2019) Impact of Somatic Yoga and Meditation on Fall Risk, Function, and Quality of Life for Chemotherapy-Induced Peripheral Neuropathy Syndrome in Cancer Survivors. Integrative cancer therapies 18: 1-16. https://doi.org/10.1177/1534735419850627

42. Kleckner IR, Kamen C, Gewandter JS et al (2018) Effects of exercise during chemotherapy on chemotherapy-induced peripheral neuropathy: a multicenter, randomized controlled trial. Supportive Care in Cancer 26(4): 1019-1028. https://doi.org/10.1007/s00520-017-4013-0

43. Mols F, Beijers T, Lemmens V et al (2013) Chemotherapy-induced neuropathy and its association with quality of life among 2-to 11-year colorectal cancer survivors: results from the population-based PROFILES registry. Journal of Clinical Oncology 31(21): 2699-2707.

\section{Figures}




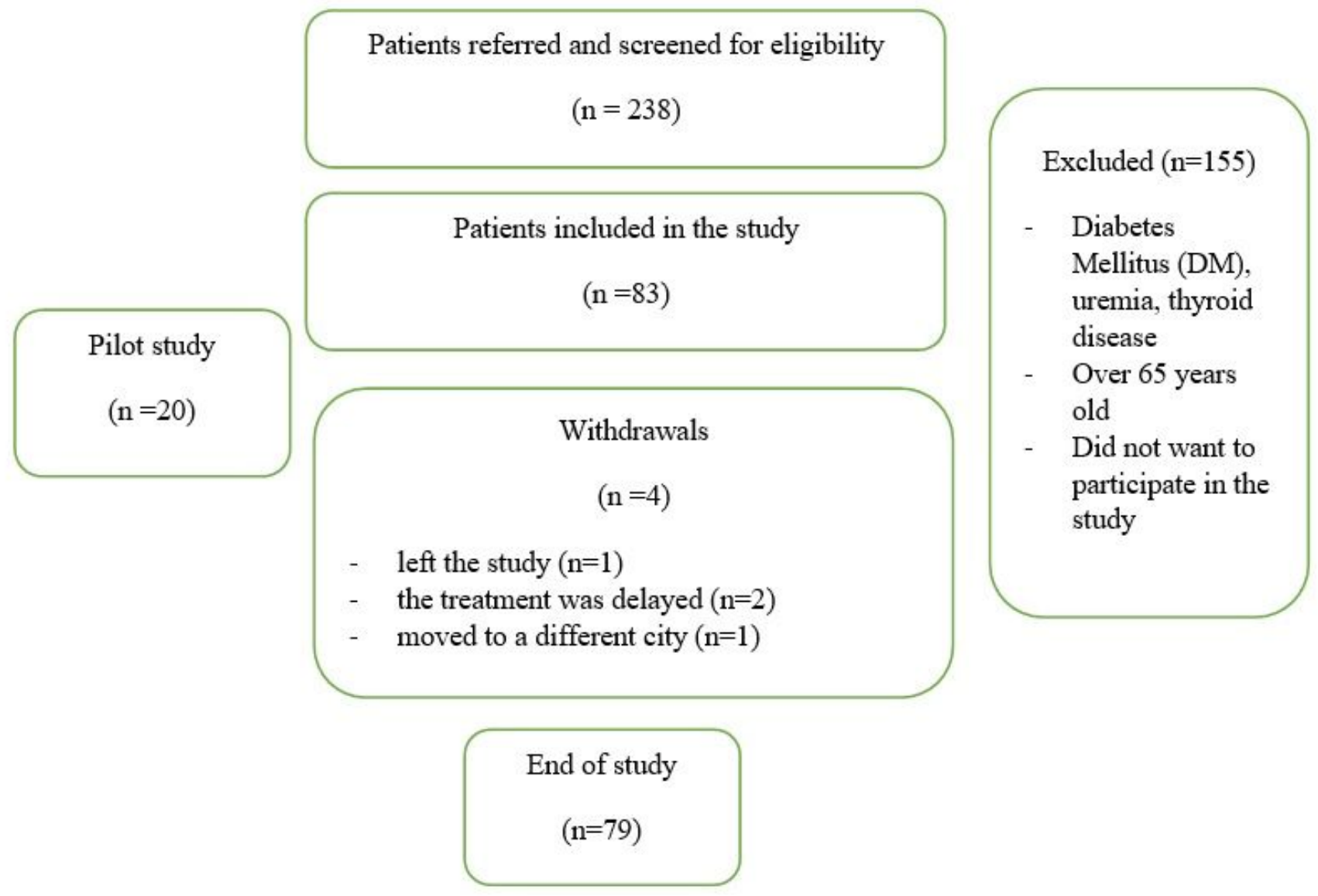

Figure 1

Flow of participants through the study 
Neuropathy_dexterity

Quality of Life

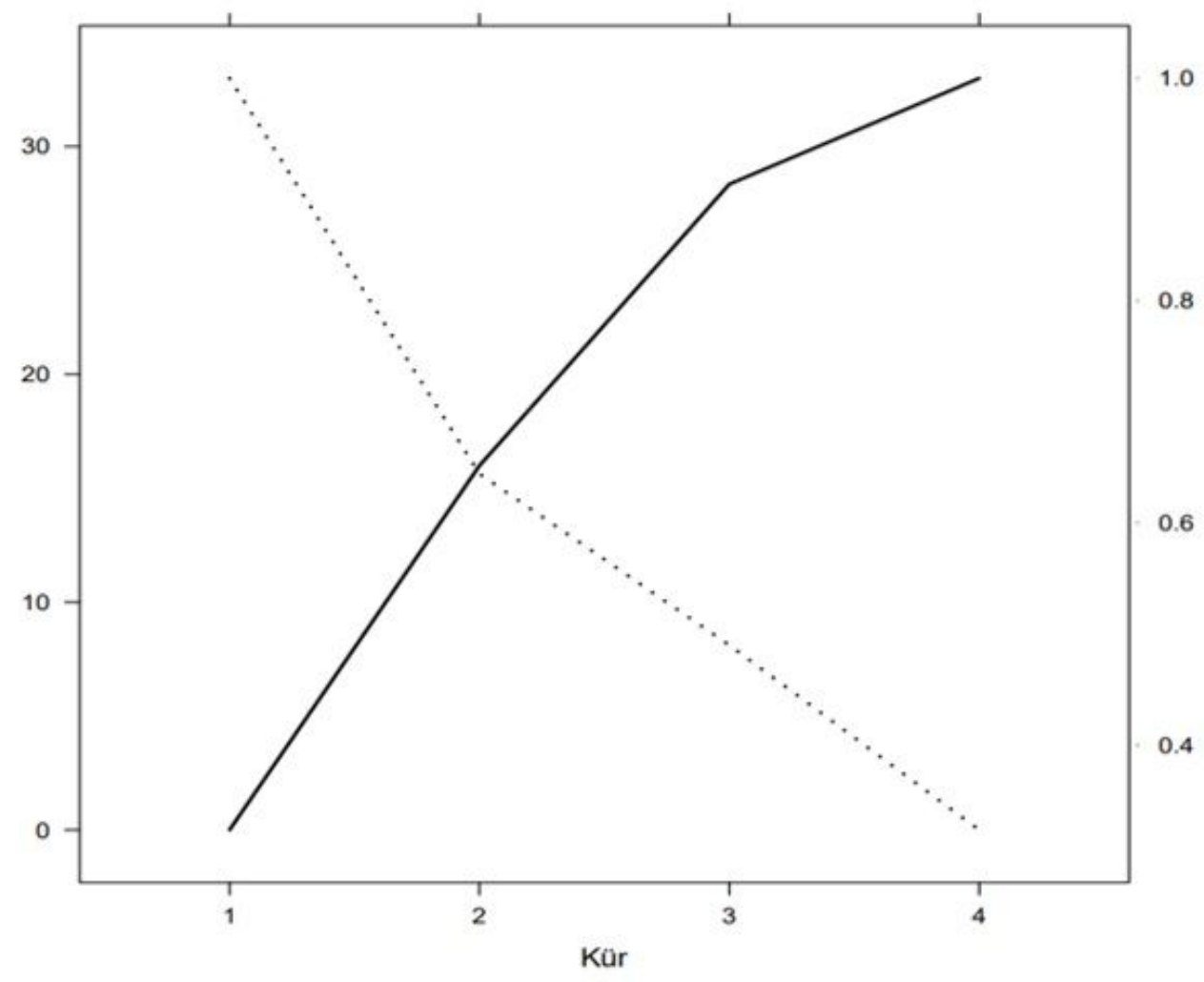

\section{Figure 2}

Graphics 1 . The relationship between the neuropathy dexterity subdimension and the functional subdimension QLQ

\section{Supplementary Files}

This is a list of supplementary files associated with this preprint. Click to download.

- SupplementaryfileSTROBEchecklistcrosssectional.docx 